\title{
Clinical features and treatment of ruptured pulmonary hydatid cyst in children
}

\author{
Tunç Özdemir ${ }^{1 \oplus}$, Ali Sayan ${ }^{1 \oplus}$, Belce Candan ${ }^{1 \oplus}$, Gökhan Köylüoğlu ${ }^{2 \oplus}$ \\ ${ }^{1}$ Department of Pediatric Surgery, University of Medical Sciences, Tepecik Training and Research Hospital, Izmir; ${ }^{2}$ Department of \\ Pediatric Surgery, Katip Çelebi University, Tepecik Training and Research Hospital, İzmir, Turkey.
}

\begin{abstract}
Backgroud and objectives. Rupture is the main complication of the pulmonary hydatid cyst (HC). The aim of this study was to evaluate the clinical features and treatment of ruptured pulmonary HC.

Method. The medical records of children who had undergone surgery between January 1999 and December 2017 for pulmonary HC were retrospectively evaluated. One hundred forty seven of these patients had ruptured $\mathrm{HC}$ at the time of diagnosis. The gender, age at the time of diagnosis, sociogeographic status (i.e., from urban or rural population group), symptoms, affected lung region, cyst dimensions, preoperative complications, medical treatment duration, and associated morbidities were evaluated.
\end{abstract}

Results. The study included 649 patients with pulmonary HC. Mean age was 9,8 (2-17) years. Three hundred forty four patients were male and 305 were female. The most common symptoms were, cough accompanying mucopurulent sputum, hydropthysis and dyspnea in patients with ruptured HC. The diagnosis of all the patients were established in the light of the findings obtained from two-sided chest x-ray and CT of the thorax. Simple cystotomy via posterolateral thoracotomy was the treatment of choice. Cappitonage was not performed in any patients. Lung resection was performed only if there was an irreversible and disseminated pulmonary destruction.

Conclusion. Rupture of the pulmonary HC is the most common and also the most feared complication. Rupture may be either intrabronchial or intrapleural. Radiologic imaging is diagnostic. Rupture of the pulmonary HC must be considered as an emergent issue. Simple cystotomy amd removal of the laminated membranes are adequate treatment of choice. Meticulous closure of the bronchial openings is mandatory to avoid prolonged air leak. Cappitonage is unnecessary.

Key words: hydatid cyst, chest, pediatric.

Uncomplicated hydatid cyst (HC) is the most common parasitic disease of the lungs. It has an endemic distribution, especially in rural areas of developing countries. The most common form is Echinococcus granulosus, which gives rise to cysts primarily in the liver and lungs. The lungs are the second most frequently involved organ following the liver. The reported incidence of HC disease in Turkey is 20 per 100,000 people. ${ }^{1}$

\footnotetext{
Tunç Özdemir

ozdemirtunc@yahoo.com
}

Received 29th March 2019, revised 9th December 2019, 18th December 2019, accepted 20th December 2019.
The growth rate of the $\mathrm{HC}$ varies in different organs. Tissue elasticity probably plays a major role in limiting the growth rate. Growth in soft organs is faster than in dense organs. It is reported that liver cysts grow at a lower rate than lung cysts.,3 Negative intrathoracic pressure may result in rapid growth of a pulmonary cyst, whereas the compact tissue and hepatobiliary system in the liver probably limit HC growth. ${ }^{4}$

Generally, pulmonary HCs are asymptomatic. In some patients, symptoms such as dyspnea, coughing, nausea and vomiting related to mass effect may occur. Pulmonary HCs, may reach to giant diamaters in pediatric population because of the higher elasticity of the lungs in this age 
group, which permits cyst expansion. ${ }^{2}$ Rupture is the main complication of cysts especially in patients with large cysts and may be related to the presence of symptoms, and to morbidity and mortality. Rupture of a cyst into the pleural space or bronchus may even cause anaphylactic reactions. ${ }^{5}$ Furthermore, obstruction of the tracheobronchial tree with cystic membrane can lead to suffocation. ${ }^{6}$

We herein report the clinical features and treatment approach of 649 pediatric patients with pulmonary HC. One hundred forty seven of the patients had ruptured pulmonary cysts.

\section{Material and Methods}

This research was reviewed and approved by institutional Ethics Comitee of University of Medical Sciences, Tepecik Training and Research Hospital (Reference number: 2019/0312).

The medical records of 649 patients (2-17 years of age) who were referred to our tertiary center and had undergone surgery between January 1999 and December 2017 for pulmonary HC were retrospectively evaluated. The patients were divided into two groups. Patients in group I had uncomplicated pulmonary $\mathrm{HCs}(\mathrm{N}$ : 502). Group II is consisted of the patients with ruptured pulmonary $\mathrm{HC}$. The preoperative 2-sided chest $\mathrm{x}$-rays and computed tomography (CT) scans of the thorax of all patients were assessed for the size, location, and complication of the cysts. Indirect hemagglutination (IHA) serology was also conducted. Demographic aspects of the patients at the time of diagnosis, sociogeographic status (i.e., from urban or rural population group), symptoms, affected lung region, cyst dimensions, preoperative complications, medical treatment duration, and associated morbidities of the two groups were statistically compared. Fisher's exact test was used for ratio comparison (number of boys and girls with cysts, number of patients from rural and urban areas, location and size of the cysts, mean hospital stay).

\section{Results}

In this retrospective study, 502 patients with non-complicated pumonary $\mathrm{HC}$ and 147 patients with ruptured pulmonary HC were treated surgically in our referral center from January 1999 to December 2017. Demographic characteristics of the patients were summarized in Table I. There were no statistically significant difference between two groups related to age, gender and sociogeographic status (Table I).

The presenting signs and symptoms of the patients from both groups are featured in Table II; some patients had more than one symptom. The most common symptom was cough accompanying mucopurulent sputum, being presented in $101(68 \%)$ patients, followed by massive hydropthysis (38\%). Dyspnea was another major complaint (34\%) in group II. Two patients were admitted with respiratory distress and cardiopulmonary arrest because of endobronchial rupture. Both patients were reanimated and survived. Thirteen patients had pulmonary abscess formation because of delayed presentation (9\%). Fourteen percent of the patients from group 1 was diagnosed with $\mathrm{x}$-rays which were taken for different purposes $(\mathrm{N}: 70)$.

Table I. Demographic characteristics of two groups.

\begin{tabular}{llccc}
\hline & & Group 1 & Group 2 & P value \\
\hline Age (years) & & 9.8 & 9.4 & 0.06 \\
\multirow{2}{*}{ Gender } & Male & $53 \%$ & $55 \%$ & 0.05 \\
& Female & $47 \%$ & $45 \%$ & 0.05 \\
\multirow{2}{*}{ Sociogeographic status } & Urban & $40 \%$ & $41 \%$ & 0.07 \\
& Rural & $60 \%$ & $59 \%$ & 0.07 \\
\hline
\end{tabular}


Table II. Signs and symptoms of patients.

\begin{tabular}{lccc}
\hline & $\begin{array}{c}\text { Group I }) \\
\mathrm{n}(\%)\end{array}$ & $\mathrm{N}$ (Group II) & P value \\
\hline Hydropthysis & $0(0)$ & $56(38.0)$ & 0.0002 \\
Cough-sputum & $55(10.9)$ & $101(68.7)$ & 0.001 \\
Dyspnea & $12(2.3)$ & $51(34.6)$ & 0.006 \\
Anaphylaxis & $0(0)$ & $11(7.4)$ & 0.0004 \\
Pneumothorax & $0(0)$ & $23(15.6)$ & 0.0007 \\
Pleural fluid & $3(0.5)$ & $47(31.9)$ & 0.0002 \\
Suffocation & $0(0)$ & $2(1.3)$ & 0.001 \\
Chest pain & $22(4.3)$ & $32(21.7)$ & 0.0007 \\
\hline
\end{tabular}

Combined lung and liver cyst were identified in 9 patients ( $7 \%$ of all patients). One patient had concomitant cranial HC. More than one cyst was present in 12 patients in group I (2\%). Ten patients had ipsilateral multiple cysts, two had contralateral. Fourteen patients of group II had multiple HCs (9\%). (8 ipsilateral, 6 contralateral). The difference between two groups was statistically significant $(p=0.007)$.

Locations of HCs regarding to pulmonary lobes were summarized in Table III. While, ratios of affected lung region according to lobes were similar, ruptured HCs were more prone to be located peripherally $(\mathrm{p}=0.0001)$.

The diagnosis of all the patients were established in the light of the findings obtained from twosided chest x-rays and CT of the thorax. In addition, all the patients were screened through abdominal ultrasound and cranial tomography. On chest $\mathrm{x}$-rays water-lily sign or Camelot sign was present in the majority of the patients in group II. "Cumbo sign" and "Dry-cyst sign" were seen in CT imaging of patients with intrabronchial rupture. The ruptured cyst was in the left lung in $82(55 \%)$ patients and the right in $65(45 \%)$. Average cyst diameter was $6.4 \mathrm{~cm}$ in group I (4-12 cm) and $8.6 \mathrm{~cm}$ in group II (7.5-17 $\mathrm{cm})(\mathrm{p}=0.004)$.

Serological tests (IHA) were positive $(\geq 1 / 128)$ in 346 patients $(69 \%)$ in non-complicated group and 96 patients $(65 \%)$ in ruptured HC group. The difference between two groups were statistically insignificant $(p=0.05)$.

In non-complicated patients, routine benzimidazole compound $10 \mathrm{mg} / \mathrm{Kg}$ twice per day therapy was started and continued 7-14 days preoperatively. In group II, benzimidazole was started and surgical therapy was planned immediately.

Standard classic posterolateral thoracotomy was used. After entering the pleural cavity, the lung was spared from adhesions of chest wall and diaphragm. Then cysts were identified and surrounded by $5 \%$ povidone iodine irrigated abdominal lap to prevent seeding of possible ruptured laminated membrane. Pericyst wall was opened and the laminated membrane was delivered and enucleated. After removal of laminated membranes, bronchial openings were identified using intrapulmonary positive pressure maneuver and closed using 2/0

Table III. Affected lung region for both groups.*

\begin{tabular}{|c|c|c|c|c|c|c|}
\hline & $\begin{array}{l}\text { Right lower } \\
\text { lobe }\end{array}$ & $\begin{array}{l}\text { Left lower } \\
\text { lobe }\end{array}$ & $\begin{array}{c}\text { Left upper } \\
\text { lobe }\end{array}$ & $\begin{array}{l}\text { Right upper } \\
\text { lobe }\end{array}$ & $\begin{array}{l}\text { Right middle } \\
\text { lobe }\end{array}$ & $\begin{array}{c}\text { Peripherally } \\
\text { located }\end{array}$ \\
\hline Group I & $175(34.8)$ & $100(19.9)$ & $90(17.9)$ & $91(18.1)$ & $46(9.1)$ & $76(15.1)$ \\
\hline Group II & $49(33.3)$ & $31(21.0)$ & 29 (19.7) & $26(17.6)$ & $18(12.2)$ & $98(66.6)$ \\
\hline
\end{tabular}

*Data shown as: $\mathrm{n}(\%)$ 
polyglactin. The cavities were left open after closure of the bronchial openings. Cappitonage was not performed in any patients. Lung resection was performed only if there was an irreversible and disseminated pulmonary destruction ( $\mathrm{N}: 7$ patients). None of the patients from group I required lung resection. The most common postoperative complication was prolonged air leak (N:5 patients, 4 in group II, 1 in group I). No further surgical intervention was necessary in these 5 patients. There was no mortality.

Mean hospital stay was 4,6 days (3-12) in group I, 7.4 days (5-21 days) in group II. The difference between two groups was statistically significant $(\mathrm{p}=0.002)$.

Postoperative benzimidazole compound therapy was continued for 3 months for both groups (Albendazole, $10 \mathrm{mg} / \mathrm{kg}$ per day, administered twice daily). Medical treatment was started 5-14 days before surgery in group I. In group II, benzimidazole compound was started immediately and surgical intervention was done without delay. The patients were followed for 32 months postoperatively (2862 months) with 6-months interval. Routine chest $\mathrm{x}$-rays were taken during follow-up. No complications were observed except temporary atelectasis which dissolves spontaneously. No reccurence was detected during follow-up.

\section{Discussion}

Pulmonary HCs are generally asymptomatic. Cyst rupture may occur. Rupture of the cyst is the most common and also the most feared complication. The rate of spontaneous rupture was $22.6 \%$ (147 of 649 patients ) in our study. This finding is consistent with the literature. ${ }^{7}$

The factors yielding perforation, such as pressure, size, and the central or peripheral location of the cysts, have been investigated in clinical studies. ${ }^{8-10}$ Expanding HCs may result in high pressure due to the low volume of the thorax leading to perforation in childhood. ${ }^{11}$ Önal et al. ${ }^{11}$ concluded that, HCs located in the right middle lobe and lingula have high perforation and postoperative complication rates in children. Therefore they recommend surgical treatment as soon as possible in these patients to prevent the risk of rupture. ${ }^{11}$ Yalin et al. ${ }^{8}$ reported that there is positive correlation between the size and pressure of the cysts in liver HC. Yuksel et al. ${ }^{12}$ argued that, as the pressure inside the cyst increases, the parenchyma surrounding the cyst becomes thinner. Therefore as the diameter of the cyst increases, the risk of direct rupture increases. ${ }^{12}$ However, Kocer et al. ${ }^{13}$ found no relationship between the size of the cyst and the risk of perforation. It was noted by Lewall et al. ${ }^{14}$ that peripherally located $\mathrm{HCs}$ rupture directly into the pleural space frequently because the pericyst layer and lung tissue that surround the cysts are very thin. Peripherally and subpleurally located HCs and increased pressure inside the cysts lead to pleural necrosis, and these factors have an effect on rupture into the pleural space. ${ }^{10} \mathrm{In}$ our study, a majority of the ruptured cysts were located peripherally. Difference between two groups was statistically significant. In our study group, we found that, $33 \%$ of ruptured HCs are located at right lower lobe of lung. However, the statistical analysis did not appear significant between two groups of our study regarding to right lower lobe location.

Rupture may be either intrabronchial or intrapleural. Inrabronchial rupture of the $\mathrm{HC}$ is mostly presented as hydropthysis, cough, dyspnea or even suffocation leading to death. Rupture of the HC into the pleural space can cause spontaneous pneumothorax, hydro-pneumothorax, tension pneumothorax, empyema and pleural thickening. Bronchial and pleural perforation rates have been reported of $21.1 \%$ and $3.6 \%$, respectively by Cangir et al. ${ }^{15}$ Ruptured HCs have been reported to have greater postoperative morbidity and mortality than intact cysts., ${ }^{716}$

Surgical treatment may be difficult in ruptured HCs due to contamination and destruction of the lung tissue. Numerous surgical procedures have been described in the literature, which, 
excision of entire cyst by enucleation (Barrett technique), excision of pericyst (Perez Fontana), cystotomy, capitonnage, wedge resection, segmentectomy and lobectomy. ${ }^{17-19}$ The choice of surgical technique depends of perioperative findings. Barrett technique, is generally preferred on peripherally located small cysts, but extirpation is difficult to accomplish without rupturing the cyst. ${ }^{18,19}$ Resection techniques are used only if parenchymal lesions seems irreversible. ${ }^{17,18}$ Because the affected lung parenchyma in children has a great capacity for healing especially for children and young adults, pulmonary resection should not be routinely performed even in the complicated cysts. ${ }^{17,18}$

The capitonnage procedure, which is considered to reduce postoperative complications, may not be possible due to infection of the pericystic tissues. And either not necessary. Capitonnage procedure has not been carried out in our patients. Lung resection was necessary in 7 patients with an irreversible and disseminated pulmonary destruction. Resections were performed to patients whose cysts were located peripherally and achieved by stapling devices. No anatomic resections were performed.

Lessons learned from 649 patients with pulmonary HCs were;

- Both genders are affected equally. However, children who live in rural area are more prone to be affected than the children who live in urban area. There was no statistically significant difference between the patients with non-ruptured and ruptured pulmonary HCs.

- Mucopurulent sputum with forceful cough, hydropthysis and dyspnea are the major complaints in ruptured HCs. Massive hydropthysis may lead to suffocation and cardiopulmonary arrest. Therefore, ruptued HCs must be considered as an emergent issue.
- Majority of the ruptured pulmonary HCs were located peripherally. Right lower lobe was the mostly affected lung area.

- "Size does matter". Larger cysts are more prone to rupture than smaller ones.

- Radiologic imaging is diagnostic for ruptured pulmonary HCs. In chest X-rays water-lily sign or Camelot sign (A cyst membrane floating on cystic water with free air above) was present in the majority of the patients. "Cumbo sign" which is described as "Presence of air fluid level within the endocyst and the air crescent among the pericyst and endocyst" on CT was seen in patients with intrabronchial rupture (Fig. 1). "Dry-cyst sign" is also common.

- Simple cystotomy and removal of the laminated membranes are adequate treatment of choice. Meticulous closure of the bronchial openings is mandatory to avoid prolongead air leak. Cappitonage is unnecessary in the lung however, especially in peripherally located ruptured $\mathrm{HCs}$, resection of irreversibly destructed lung tissue facilitates postoperative recovery. Anatomic resection of the lung lobes should not be done. Stapling devices may be used in simple lung tissue resections.

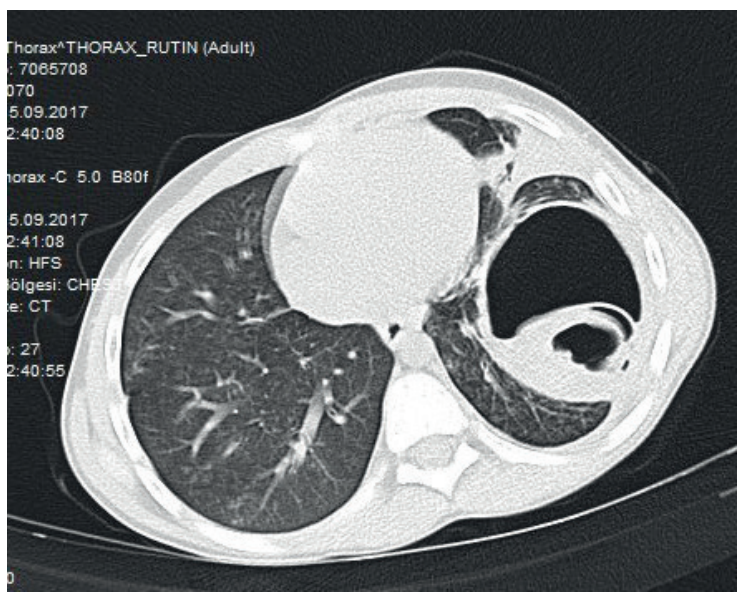

Fig. 1. Cumbo Sign of ruptured pulmonary hydatid cyst in CT. 
- Medical treatment with benzimidazole compound, either albendazole or mebendazole, is mandatory in the treatment of pulmonary HC. In non-complicated patients, medical treatment must be started 5-14 days preoperatively. ${ }^{20}$ In patients with ruptured pulmonary $\mathrm{HC}$, benzimidazole compound should be started preoperatively and must be continued postoperatively. Owing to their hepatotoxicity, a 1-week to 2-week interval should be given between 3-week and 4-week cycles and treatment may last 3 to 6 months.

\section{REFERENCES}

1. Dakak M, Genc O, Gurkok S, Gözübüyük A, Balkanlı K. Surgical treatment for pulmonary hydatidosis (a review of 422 cases). J R Coll Surg Edinb 2002; 47: 689-692.

2. Halezeroğlu S, Çelik M, Uysal A, Senol C, Keles M, Arman B. Giant hydatid cysts of the lung. J Thorac Cardiovasc Surg 1997; 113: 712-717.

3. Larrieu EJ, Frider B. Human cystic echinococcosis: contributions to the natural history of the disease. Ann Trop Med Parasitol 2001; 95: 679-687.

4. Dincer SI, Demir A, Sayar A, Gunluoglu MZ, Kara HV, Gurses A. Surgical treatment of pulmonary hydatid disease: a comparision of children and adults. J Pediatr Surg 2006; 41: 1230-1236.

5. Usluer O, Ceylan KC, Kaya S, Sevinc S, Gursoy S. Surgical management of pulmonary hydatid cysts: is size an important prognostic indicator? Tex Heart Inst J 2010; 37: 429-434.

6. Aletras H, Symbas PN. Hydatid disease of the lung. In: Shields TW, LoCicero J III, Ponn RB (eds). General Thoracic Surgery. (5th ed). Philadelphia: Lippincott Williams \& Wilkins 2000: 1113-1122.

7. Balcı AE, Eren N, Eren Ş, Ülkü R. Ruptured hydatid cyst of the lung in children: clinical review and and results of surgery. Ann Thorac Surg 2002; 74: 889892.
8. Yalin R, Aktan AO, Yegen C, Dosluoglu HH. Significance of intracystic pressure in abdominal hydatid disease. Br J Surg 1992; 79: 1182-1183.

9. Burgos L, Baquerizo A, Munoz W, de Aretxabala $\mathrm{X}$, Solar C, Fonseca L. Experience in the surgical treatment of 331 patients with pulmonary hydatidosis. J Thorac Cardiovasc Surg 1991; 102: 427-430.

10. Özer Z, Cetin M, Kahraman C. Pleural involvement by hydatid cysts of the lung. Thorac Cardiovasc Surg 1985; 33: 103-105.

11. Önal Ö, Demir ÖF. The relation between the location and the perforation rate of lung hydatid cysts in children. Asian J Surg 2018; 41: 422-426.

12. Yuksel M, Kir A, Ercan S, Batirel HF, Baysungur V. Correlation between sizes and intracystic pressures of hydatid cysts. Eur J Cardiothorac Surg 1997; 12: 903-906.

13. Kocer B, Gulbahar G, Han S, Durukan E, Dural $\mathrm{K}$, Sakinci U. An analysis of clinical features of pulmonary giant hydatid cyst in adult population. Am J Surg 2009; 197: 177-181.

14. Lewall DB. Hydatid disease: biology, pathology, imaging and classification. Clin Radiol 1998; 53: 863874.

15. Cangir AK, Sahin E, Enon S, et al. Surgical treatment of pulmonary hydatid cysts in children. J Pediatr Surg 2001; 36: 917-920.

16. Findık G, Aydogdu K, Hazer S, et al. The management of postoperative complications in childhood pulmonary hydatid cysts. Turk J Thorac Cardiovasc Surg 2012; 20: 850-856.

17. Doğan R, Yüksel M, Çetin G, et al. Surgical treatment of hydatid cysts of the lung: report on 1055 patients. Thorax 1989; 44: 192-199.

18. Aytaç A, Yurdakul Y, Ikizler C, Olga R, Saylam A. Pulmonary hydatid disease: report of 100 patients. Ann Thorac Surg 1977; 23: 145-151.

19. Dhaliwal RS, Kalkat MS. One-stage surgical procedure for bilateral lung and liver hydatid cysts. Ann Thorac Surg 1997; 64: 338-341.

20. Brunetti E, Kern P, Vuitton DA; Writing Panel for the WHO-IWGE. Expert consensus for the diagnosis and treatment of cystic and alveolar echinococcosis in humans. Acta Trop 2010; 114: 1-16. 